\title{
CrimRxiv
}

\section{Investigating sentence severity with judicial open data: A case study on sentencing high-tech crime in the Dutch criminal justice system}

Pieter Hartel, Rolf + Wegberg, Mark van Staalduinen

Published on: Feb 20, 2022

DOI: $10.21428 / c b 6 a b 371 . c 45 c c a e a$

License: Creative Commons Attribution 4.0 International License (CC-BY 4.0). 
